\title{
Culturally-based and Culturally-biased Aspects of Knowing the Other
}

\author{
Elena A. Makarova ${ }^{1, *}$, Elena L. Makarova ${ }^{2}$ \\ ${ }^{1}$ Taganrog Institute of Management and Economics, Taganrog, 347900, Russian Federation \\ ${ }^{2}$ Southern Federal University, Taganrog, 347900, Russian Federation \\ *Corresponding Author: makarova.h@gmail.com
}

\section{Copyright (c) 2013 Horizon Research Publishing All rights reserved.}

\begin{abstract}
Interaction of cultures calls for cultural awareness development. Knowledge is a powerful weapon to overcome prejudices, stereotyping and xenophobia. To build cultural awareness and tolerance to the peculiarities of someone else's culture, global learners must learn how to determine the existence of differences between cultures and how to adapt their own behavior to a foreign culture. In today's world, many problems arise because of the errors in communication, because people feel impossible "to find a common language." Communicative interactions can be successful or can result in a complete failure depending on many factors: the availability of linguistic competence of the conversation participants, on cultural and communicative competence of the parties of communication event, i.e., whether or not they have common linguistic and cultural background knowledge and what is the balance between the common and different in their processes of perception and symbolic systems.
\end{abstract}

Keywords Cultural awareness, Ethnocentrism, Communicative competence, Tolerant behavior, Non-verbal communication, Cognitive structures, Schema

\section{Introduction}

The 21-st century is the time of extremely active interaction of cultures. Expansion of international diplomatic and trade contacts, training and work in other countries, the creation of the World Wide Web, and even war served as a catalyst for the contact of cultures. Recently a new area of expertise has appeared - theory of intercultural communication, which examines issues of contact and interaction between cultures. The problem of cultural awareness is one of the questions under consideration.

Inextricably linked with the cultural interaction is tolerant behavior development and cultural stereotypes overcoming. Representatives of various cultural groups in the world think, feel and act differently. There is no unified scientific standard to define one group as superior or inferior to another.
Research of cultural differences in different groups and societies calls for position of cultural relativism, objective evaluation of different groups or societies. Knowledge is a powerful weapon to overcome ethnocentrism. By ethnocentrism we mean the beliefs that own culture is superior to others. Ethnocentrism ignores national differences; different from usual means inadequate, incorrect and therefore unworthy of attention or even dangerous.

Information about the nature of the cultural differences between societies, their roots and their effects must anticipate evaluation and action. Only the availability of cultural background knowledge makes it possible to develop preconditions for successful communication. Cultural differences lead to special variety called intercultural communication, where people from different cultures use special language options and discursive strategies, compromise approaches and knowledge about the culture of communication partner in the situation of direct contact.

Semantic-oriented value of Humanities is due, primarily, to the object of their study, and this object is culture. Culture is a set of phenomena associated with human values and generated for the sake of those values. The essence of culture is a world of human values. The world culture is as infinite as outer space; this fact causes extreme difficulties in its learning. If we consider nature as the being of things and as the most generic term of Natural Sciences, the most generic term for the Humanities is culture as a social form of human existence.

\section{Cultural Awareness Development}

The main feature of the culture study is cultural sensitivity. Other features take various forms from material artifacts to behavioral norms (family relations, economic relations, legal sanctions) - and to abstract concepts and beliefs. All of these diverse manifestations have one common feature they are symbols and as such, express the value [1]. To build cultural awareness and tolerance to the specificities of someone else's culture, students must learn how to determine the existence of differences between cultures and how to 
adapt their own behavior to a foreign culture. Some aspects can and should be learned consciously, but others are unconscious. Familiarity with foreign cultural system can be an arduous task, but if it is achieved, it definitely helps cope with other aspects of life in foreign countries, among them the foreign language and extra-linguistic phenomena of the foreign culture take a very important part.

In the communication process people exchange messages, i.e. the transmission of information from one participant to another occurs. The information is encoded using a symbolic system, passed and then decoded, or interpreted by the addressee of the message. The most important types of symbolic behavior in the human community are the use of language and the accompanying nonverbal behavior. Nonverbal communication is behavior, signaling about the character of interaction and emotional states of communicating individuals, and it is an additional source of information to actual verbal communication. The following forms of non-verbal communication are emphasized: extra-linguistic components, which include interjections, sounds expressing emotions such as shrieks, screams, moaning, and such peculiarities of speech as pitch, intensity of sound and timbre. In addition, as emotional indicators hesitation, slips of the tongue, pauses and complete silence, eye contact, mimic expressions; posture and gestures; eye movements (frequency and length of the eye fixation of another person); proxemics (interpersonal distance) can be considered [2].

\section{Linguistic and Cultural Background Knowledge}

In today's world, many problems arise because of the errors in communication, because people feel impossible "to find a common language." Communicative interactions can be successful or can result in a complete failure depending on many factors: the availability of linguistic competence of the participants in the conversation, on cultural and communicative competence of the parties of communication event, i.e., whether or not they have common linguistic and cultural background knowledge and what is the balance between the common and different in their processes of perception and symbolic systems. It can be said that the success of any communicative event rests on the three important issues: linguistic, communicative and cultural competence of communicative interaction participants.

Cultural background knowledge of communication participants is the foundation of any communication. From the time of birth, every person belongs to multiple groups, and they shaped his/her cultural competence while larger groups, usually called cultures, substantially determine the cognitive and pragmatic basis of communicative activities in any community. In everyday life people rely on mental constructs, models, mind maps, schemas, and the world image to organize their perceptions and define the way to achieve their goals. These models make up a large part of the structure of the unconscious, on which our conscious thinking and decision-making are based [3].

These cognitive structures tell us what everyday objects are; help define situations, people, and their role in activities, as well as the role that we would like to play in life. In fact, these are the models of the physical, social and psychological world we live in, and our place in it not only as physical and physiological units but also as members of society. Communication is a distinctive feature of any society; it is a complex, symbolic, transactional and often unconscious process. It allows communicants to express some external information, their inner emotional state, as well as the status role in which they are interrelated [4]. Communication occurs only because people have common knowledge in addition to idiosyncratic. Many schemas (mental or cognitive constructs), which are formed in human memory, are common not for all the humanity, but at least for the most part of it. They are an important part of the common (background) cultural knowledge and form the basis for successful intercultural communication and full-fledged communicative interactions. Communication is an interactive process, it usually requires the parties to have an image of the world in mind, and that is, their statements should be based on the same cultural background knowledge. Successful communication depends on the cultural background knowledge development and how much they are the same in the memory of interlocutors. The goal of communication includes transmission and reception of information, creation of new information, developing and maintaining relationships, cultural interaction and impact [5]. Culture consists of specific and implied behavior samples, transmitted by the symbols that make up the significant achievements of human communities. The core of the culture consists of traditional ideas and specific values; system of culture can be seen as an output or as a strategy for further action or human behavior. Ability to develop communicative competence applies to all representatives of the human race, but an implication of this potential depends on culture [6].

In addition, culture is unique and individual experience of everyone, which means that communication is a process constantly creating and recreating meanings, because even the people who speak the same language, have grown up in one and the same cultural background do not have the same cultural background. It goes without saying that in case of different cultures and different languages; communication is complicated or even becomes impossible.

Cultural differences lead to a special kind of communication called intercultural communication, where parties coming from different countries should use special language options and discursive strategies in situation of direct contact. The term 'intercultural communication' was intended for situations where communicative competencies are so different that they affect the communication event output, distort the meaning of the message or lead to the total failure of communication event. 


\section{Teaching and Learning about Culture}

Studies of foreign cultures not only introduce learners to the phenomena, language, customs and traditions, unknown to them by creating the cultural environment, but also develop their own cultural background knowledge available which in turn, contributes to a better understanding of phenomena and processes occurring within the unknown culture. Social groups usually determine cognitive and pragmatic basis for communication. All people live in society and they have to communicate with other people almost all the time - at home, at work, in social groups to which they belong, and in society as a whole. No matter how well they understand each other, communication is always a difficult task and intercultural communication is doubly complicated. Culture is what usually causes misunderstanding or incomplete communication. It affects people's approaches in different issues, place they occupy at work, their social roles in separate social groups in particular and society in general.

Culture is a very complex concept; there are many different definitions, some of them very complicated. In brief, culture belongs to a social group or community members of which share common memories and life experiences, thus contributing to understanding of the world. There are the groups to which people belong by birth, such as gender, race, or nationality. Besides, there are groups which people join later in their life. For example, a person can join a new culture by moving to another region, changing his/her social status, losing employment or becoming homeless. When we define culture as shown above it is so common that a lot of people normally belong to multiple cultures at the same time [7].

Recent psychological-pedagogical research has shown that teaching languages should focus not only upon linguistic aspects, but also on cultural knowledge as a necessary aspect of communicative competence [8, 290-310]. In addition, it is very important for a learner to be able to activate the available background knowledge at the right moment, and to retrieve the communicative schema needed for a conversation from long-term memory. And here we can refer to introjection of schemas and background, which is to ensure that communication takes place. Introjection is the individual's inclusion of other people's motivations and attitudes in his/her inner world which becomes the foundation of his/her own identity. We consider introjection as epistemology concept according to which consciousness is limited to the range of a person's own ideas and makes him/her able to understand the outside world only by projecting the outside world onto his/her mind content, it is a psychological mechanism playing an important role in the process of creating background knowledge and retrieving this knowledge back into cognitive constructs (schemas). According to Sandor Ferenczi, introjection is "the psychoanalytic concept of the inclusion of the outside world into a person's internal mental structure through identification in order to communicate a person's emotions and feelings."[9]

Introjecion means "blurring" of specific knowledge in cognitive schemes and their transition into the background knowledge, as well as retrieving background knowledge back into the schemas. Retrieving is seen as 'playing back' some time after memorizing when direct playback is not available. Introjecion mechanism supports personal meanings of the individual - this means that the information that has personal priority is understandable and structurally arranged, is best to remember and to retrieve from long-term memory. Introjecion is applied in cases of communication in the mother tongue, but it can definitely occur in a foreign language too, in cases of intercultural communication.

According to A.N. Leontiev, the communication activity can not be understood as a mere transfer of some information from one person to another. He considers communication as interaction between people in society, above all, interaction between people as members of society, as "public individuals" [10]. For successful development of communicative skills, communication between different individuals should be based on the same background knowledge; they should share the same mental schemas. Many of the schemas that people develop are unique and idiosyncratic as each person has his/her own life experience and develops his/her own views. However, the communication occurs because people also have common knowledge. Common schemas are an important part of general cultural knowledge, form the basis for successful intercultural communication and interaction and help culturally-based communicative competence. What is this? What does it consist of?

The first is knowledge of the symbol system the communication is based on, the second is the knowledge of the outside world. Knowledge about the outside world is the personal experience of the individual, the fundamental knowledge about the world available to all people and all the knowledge they possess because of their belonging to different national, ethnic, social, religious, professional, and other groups. Knowledge is stored in cognitive structures, indivisible and inseparable cognitive units. Cognitive structures that store "compressed knowledge" and/or concepts in a certain way correlate with various types of competences: they form a person's competence and lie in its foundation. Recently, cultural (and intercultural) competence has attracted researchers' major attention. Intercultural communication competence is defined as the process of direct interaction of cultures, the process that takes place within the framework of differing national mental stereotypes and behavior that significantly affect the parties' mutual understanding in the process of communication [11].

The problem of meanings is closely connected with the levels of culture. Meaning occurs at all levels of culture, and this process involves entering some information from outside into the system and its specific transformation during the movement between the input and output systems. This type of system - from minimal semiotic units to global 
cultures - has different structural isomorphism. The social nature of language not only requires learning about the new language code, but also involves acquisition of new national culture and exploration of its wealth. These regulations stipulate another aspect in mastering language - country study or cultural competence, familiarity with the modern reality of national realities, the overall culture of the country of the language, mastering the national cultural semantics and cultural function of language.

As communication is a two-sided process, its success depends on how much interlocutors' cultural knowledge match, whether there is one and the same meaning behind words they use. Schemas are sets of concepts that participants of any communication event share; that can be activated and used in case of need. Various and numerous facts and knowledge of each person are organized into mental units which we call cognitive schemas. They serve to directly connect cultural and psychological processes. Culture is considered the most important source of schemas, which play an important role in most psychological processes. Thus, schemas are the way culture affects other psychological processes, what in turn affects other spheres of human activities.

\section{Cognitive Structures in Communication}

Cognitive schema is unconscious way of interpreting events, forcing people to see the outside world from a certain cultural-determined perspective and act according to its culturally determined interpretation of world events. Cognitive schemas generate one another and form a kind of a web-like structure; through these networks of cultural and cognitive schemas the whole information about the world outside is processed. Any learning is based on a network view of reality.

Current research examines the impact of culture on individual subjectivity, behavior and education. Theoretical discussions are held on how collectively interpreted experience creates a foundation for individual's thinking, thus developing conditions for his/ her successful training in the system of education. One of the main issues discussed today is the basis of background knowledge and how it can be activated to understand and memorize information in the process of education. In this research educational space is represented as heterogeneous semiotic space. Each semiotic space sets its own semantic context, has its own emotional overtones and dictates its rules of activity development; it describes its own reality of human insight, memories of the past, visions of the future, the reconstruction of the historical era or the image itself [12]. In the current context of the statement that "the center of human existence is being shifted to the pole of culture", the inclusion of culture in educational process is quite natural [13]. Learning foreign languages is intended not only for provision of students with some amount of linguistic knowledge, but also for helping them overcome difficulties of intercultural communication, acquire cultural awareness and build skills that will surely come in handy in their future professional activities.

In a diverse world, there are many factors that affect molding of personal identity, and culture is one of the most powerful forces that are involved in this process. "Culture of everyone gives him/her a 'lens', through which he/she sees the world," logical explanation of "how the world is arranged, grammar, through which he/she acquires meaning" [11, 182]. In other words, the culture explains how people extract meaning from what is seen, and how they express it using words. As soon as people belonging to different cultures unite to accomplish some assignment, cultural values often come into a conflict. People don't understand each other; react in a way that hinders their joint work that was anticipated to be a successful partnership. And in most cases, people do not see culture behind this failure. Very often they do not even understand that their cultural values or beliefs are very different from those of others. When a person he doesn't understand other people there is usually a long list of prejudices, stereotypes, fear of misunderstanding and fear to hurt someone unintentionally. When dealing with other people, there is only one similarity - they also have a long list of expectations and fears [14].

\section{Six Major Cultural Differences}

Cultural knowledge may help not only in understanding others, but also in self-understanding. Exploring ways of different groups of people interaction within the community becomes a key opening a channel of intercultural communication. There are six major cultural differences. Anyone who is involved in intercultural communication should be aware of these common differences. In case of disagreement or misunderstanding, it is necessary to review how culture can influence decision-making; moreover, there is a certain need to get a different view of the problem, to look at it from another perspective and through the eyes of the communication partner. Six major cultural differences are:

Different communication styles. This is the way people are engaged in communication within one culture. One aspect of a communication style is language itself. In different languages and cultures, the words and expressions are used in different ways. For example, in the English-speaking cultures the meanings of simple words such as 'Yes' and 'No' vary from "maybe I'll think it over" to "definitely" and "absolutely" with a wide range of meanings in between. Another important aspect of communication style is non-verbal communication. It includes facial expression, gestures, posture, distance between interlocutors, time sense. In addition, various degrees of insistence in communication can lead to confusion. For example, an American will consider an interlocutor's raised voice as a signal for a dispute, while Italians, Africans and Mexicans believe that raising voices in 
the conversation only enhances its attractiveness because it points to the interest of the parties to the problem discussed. Thus, an American may not adequately respond to loud debate with people of other cultures, becoming aggressive and getting involved in the dispute.

Different attitudes to conflicts. In certain cultures a conflict is considered as a positive phenomenon, while others try to avoid it. In the United States, for example, the conflict is not desirable in the everyday situation, but people are encouraged to resolve conflicts as they occur rather than avoid them. They are recommended to meet eye-to-eye as one way to resolve the problem. On the contrary, in many European countries a conflict causes embarrassment and humiliation, people are recommended to settle conflicts peacefully, thereby avoiding confrontation or meeting face-to-face. Letters or messages exchange is one of the most favorite European ways of conflict resolution.

Various approaches to assignment accomplishment. Depending on the culture, people choose different ways to accomplish their assignments. This includes various accesses to information sources, opinions about job reward, time sense and different attitude to business relationship. When collaborating in business, people differ in their attitudes to interaction and relationship at the early stage of this collaboration. In Asian and South American cultures, great attention is paid to the development of relations in the early stages of joint project implementation, and the importance is increasing towards the end of the project, while in the European and American culture, the relations are built during work on the joint project. This does not mean that people in one culture are more dedicated than others, or they value human relationships more than a job. It means that they participate in achieving their ultimate goal differently and come to it in different ways.

Various decision-making styles. The role people play in decision-making s various in different cultures. For example, in the United States the decision-making responsibility is shared. In many southern European countries and in Latin America, great importance is paid to individual decision-making responsibility. When a decision is to be taken by a group of people, the majority rule is a conventional approach; consensus is preferred in Japan, for example. It must be mentioned that people's expectations about their roles in the decision-making can be culture-biased.

Different attitude to sincerity. In some cultures people do not show their emotions or share personal information which might cause a conflict or misunderstanding. It should be kept in mind when taking part in intercultural communication. People from different cultural background also differ in the way they behave in public. Questions that are natural in some cultures (which was the conflict? what is your role in the conflict? what are the consequences of the conflict?), seem like interference in privacy according to the cultural rules of others. There is a difference in the information disclosure; the degree of sincerity should also be considered before dealing with other cultures, judging points of view, drawing opinions about other people.

Different approach to knowledge. Significant difference exists between cultural groups when it comes to how people acquire knowledge. European cultures apply cognitive methods such as calculating and measuring in information search, regarding them more reliable than other methods. While in African cultures, preference is given to such methods as symbolic images and rhythm. Asian cultures have focused on such methods of learning as investigating the mysterious and incredible [10, 20-21]. Different approaches to knowledge affect the problem analysis or ways to solve them. While studying different approaches may help understand cultural limitations; recognition of cultural differences may help in understanding what it means to be different from the other. Knowledge of the above six differences may help understand people from different cultures better.

When faced with something that is beyond their comprehension, people tend to identify this as 'abnormal', 'false', 'strange' [15]. This tendency is likely to increase from the individual resistance to prejudice, stereotyping, or even xenophobia. The danger is that if this tendency, consciously or unconsciously, is embedded within the organizational structures, prejudice will take root in all structures - in laws, policies, mass media, and other spheres of life. That is why it is important to learn how to control this tendency to substitute the phrase "other than me" for "worse than me." The word 'tolerance', so fashionable nowadays, must be changed from a simple slogan to motto of everyday life. Young people should be taught how to work together, to bridge cultural gaps, to cross cultural borders both individually and as a society as a whole. Understanding cultural differences does not separate people. On the contrary, the more students are aware of cultural differences, the more it helps them more effectively communicate with each other. Understanding that cultural differences can and should work for communication is just the first step towards mutual understanding and respect for the others.

\section{Conclusion}

Up until present, the belief in the separation of a language and culture prevailed in foreign language teaching. This practice led to students being introduced to the culture after learning the foreign language or not being introduced to it at all. Currently, language teachers have promoted the idea that language and culture are connected and interactive, that language is "a social semiotic... a social signifying practice" and that if "language is seen as social practice, culture becomes the very core of language teaching" [16, 5-12]. Thus, the language curriculum should emphasize teaching and learning culture as well as language. Culture is the sum of special knowledge that accumulates a lot of things: the way people dress, eat, carry their heads, walk, talk, mimic and gesticulate, tie their ties and wear their hats; it is not only the fact of writing books, or composing music and painting 
pictures. Popular culture is the way of life, the social legacy the individual acquires from a social group, a way of thinking, feeling, and believing. It is also a learned behavior and as a body of learned behaviors common to a given human society, shapes consciousness within a human society from generation to generation.

The major problem of many students learning English is lack of cultural knowledge. Even though they speak fluent English they tend to experience cultural difficulties in communication with people from a different cultural background. Through its careful attention to human experience, language education has revealed an enduring ability to usefully intervene and make explorations into culture and cultural practice a subject of study. Yet how might 21 st century education better attune itself to the opportunities and challenges implied by attempts to understand contemporary culture and cultural experience "from the inside"? Indeed, what limitations or boundaries are implied by efforts to study different cultural practices through learning a foreign language and what might this mean for educators' contribution to teaching theory? These and many other questions are still to be answered. It can be done with contributions from across the sciences and shared methodological and theoretical insights, carefully gleaned problems solutions in the course of each science own study of culture. Among the sciences involved in this study, sociology and social policy, psychology, media and communication studies, cultural studies, social/cultural anthropology and other allied disciplines should be mentioned.

Learning how to communicate with other people enriches human life. Different communication styles reflect deeper philosophies and worldviews that exist in different cultures. Understanding these philosophies gives a broader picture of what the world has to offer. Exploring different cultures could become a mirror, in which students will see their own cultural awareness. They will have a chance to verify their assumptions and consider several alternative approaches, a chance to explore new ways to solve problems, to take cultural differences for granted as a starting point for solving international problems rather than an intercultural communication end.

And finally, if a person is open-minded to any cultural knowledge, he or she will bridge the gap between the cultures. Stereotyping separates people who could become friends or business partners otherwise. Contacts of people who differ in many respects improve our society and the world in general. That is why culture should be considered an obligatory course in any foreign language course.

The role of language teachers is to help students develop their cultural background knowledge and thus help them find their role in intercultural communication in general and in foreign language discourse in particular. This approach shows the importance of schemata and cultural background knowledge introjection for the success of acquiring intercultural communication skills and the development of tolerant behavior in order to overcome cultural prejudices.
Our research focuses on cultural knowledge as an educational objective in its own right. The focus is on cultural features of the society and development of tolerant behavior and attitudes, on culture and how to integrate it into English language teaching course. We believe that knowing about culture helps students easily integrate into the global community and feel at home in any country of the world. Difficulties of teaching English as a foreign language are based on the fact that it takes place in the absence of linguistic and cultural environment, and students are deprived of any possibilities to communicate in English outside their classroom.

Learning about culture can be done in many different ways: taking part in English language club activities, writing to a pen pal, traveling abroad, participating in the Work \&Travel program, taking advantage of summer linguistic schools or student exchange programs, living in the family as an Au Pair and many others. Among other programs are home-stays, allowing students to experience the lifestyle and culture from within the homes of its native people. There is no better way to learn a language of a foreign country than by being immersed in the culture of its native speakers.

\section{REFERENCES}

[1] L. White. The Science of Culture. N.Y., 1949.

[2] V. Labunskyaâ. Non-Verbal Behavior (social and perceptual approach). -Rostov-on-Don, 1986. -136 p.

[3] J. Anderson. Cognitive Psychology and its Implications. New York: W. Freeman and Co., 1990.

[4] P.L. Carrell. Schema Theory and ESL Reading: Classroom Implications and Applications. Modern Language Journal, 1984, V 68, n 4, pp 32-43.

[5] R.W. Casson (ed.). Language, Culture, and Cognition: Anthropological Perspectives. New York: Macmillan, 1981, pp. 20-21.

[6] R.G. D'Andrade. The Culture Part of Cognition // Cognitive Science. 1981, №5, p. 182.

[7] A.F.C. Wallace. Culture and Personality. New York: Random House, 1960.

[8] P. Whitney. Psychological Theories of Elaborative Inferences: Implications for Schema-Theoretic Views of Comprehension. Reading Research Quarterly, 23 1987: 299-310.

[9] S. Ferenczi. Introjektion und Ubertragung // Jahrbuch fur Psychoanalyse und psychopath. Forsch. 1, 1910, p. 422-457, in Russian translation. Odessa, 1925

[10] A.N. Leontiev. Activities. Consciousness. Personality. 2nd Edition. Moscow: Politizdat, 1977.

[11] I.A. Sternin. Communicative Behavior in the Structure of National Culture//Communication in the light of the theory of reflection. Frunze, 1980. 
[12] Yu. Lotman. Semiosphera. St. Peterburg, Art — St. Pb, 2000.

[13] V.S. Bibler. From Science to the Logic of Culture (Two philosophical introductions in the twenty-first century). Moscow: Political Literature, 1991.

[14] I. Prigozhin, I. Stengers. The Order out of Chaos: a New Dialogue of Man and Nature. Ed. V.I. Aršinova, Y.I. Klimontovič and J.V. Sačkova. Moscow: Progress, 1986
[15] V.B. Švyrkov. Introduction to Objective Psychology. M.: Institute of psychology of the RAS, 1995

[16] Kramsch, C. Foreign Languages for a Global Age. ADFL Bulletin, 1993, 25 (1): 5-12. 